\title{
Indicadores de qualidade da água e padrões de uso da terra em bacias hidrográficas no Estado do Paraná
}

\author{
Daniel Ruiz Potma Gonçalves ${ }^{(1)}$ e Carlos Hugo Rocha(1)
}

(1)Universidade Estadual de Ponta Grossa, Departamento de Ciência do Solo e Engenharia Agrícola, Avenida General Carlos Cavalcanti, no 4.748, CEP 84030-900 Ponta Grossa, PR, Brasil. E-mail: drpgonc@gmail.com, chrocha@uepg.br

Resumo - O objetivo deste trabalho foi determinar a relação dos indicadores de qualidade da água com o regime de chuvas e os padrões de uso da terra. Foram avaliadas quatro bacias hidrográficas e suas respectivas áreas de preservação permanente (APPs), fontes do reservatório Alagados, no Estado do Paraná. O uso dos solos nas bacias e nas APPs foi mapeado em ambiente de sistema de informações geográficas, e os padrões resultantes foram avaliados quanto ao índice de qualidade das águas (IQA) e ao regime pluvial. A qualidade das águas foi menor nos períodos de verão, quando há maior precipitação e manejo mais intensivo dos solos, com presença de maiores superfícies cultivadas na paisagem. A área total cultivada nas APPs teve efeito negativo sobre a qualidade das águas. Diferenças topográficas, geomorfológicas e pedológicas, bem como sua influência nos padrões de uso dos solos, foram discutidas para possível explanação dos valores observados de IQA nas bacias. A variabilidade dos padrões de IQA entre as bacias, bem com os valores extremos observados de acordo com as estações do ano, evidencia a necessidade de gerenciamento do uso das terras, particularmente no âmbito das APPs, para que sejam mantidos padrões desejáveis de vazão e qualidade das águas do manancial.

Termos para indexação: agricultura intensiva, áreas de preservação permanente, recursos hídricos, planejamento territorial, poluição não pontual.

\section{Indicators of water quality and land usage patterns in watersheds in the state of Paraná, Brazil}

\begin{abstract}
The objective of this work was to determine the relationship of water quality indicators with rainfall regime and land use patterns. Four watersheds and their respective permanent protected areas (APPs), sources of the Alagados reservoir, in the state of Paraná, Brazil were evaluated. Land use at basin level and in the APPs were mapped in a geographic information system environment, and the resulting patterns were evaluated as to their relation with the water quality index (IQA) and rainfall regime. Water quality decreased in the summer periods, when higher average rainfall and more intensive land management were present, with larger cultivated areas in the landscape. Total cultivated area in the APPs had negative effect on water quality. Differences in topography, geomorphology, and soil types, as well as their effect on land use patterns, were discussed as a potential explanation for the observed values of the IQA in each basin. The variability of the IQA patterns among watersheds, as well as the extreme values observed according to the season, highlights the demand for land use planning, particularly within the APPs, in order to ensure desirable patterns of water flow and quality in the wellspring.
\end{abstract}

Index terms: intensive farming, permanent protected areas, water resources, territorial planning, non point pollution.

\section{Introdução}

Na região dos Campos Gerais do Paraná, a bacia hidrográfica da represa de Alagados, formada pelos rios Pitangui e Jotuba, é responsável por cerca de $30 \%$ do abastecimento da cidade de Ponta Grossa, que tem uma população estimada de 330.000 habitantes. As águas da represa de Alagados vêm apresentando, desde o final da década de 1990, excessivo crescimento e florescimento de algas cianobactérias, o que tem contribuído para diminuir sua qualidade e onerar custos de tratamento (Bacia..., 2002; Pereira \& Moro, 2012). Cianobactérias da espécie Cylindrospermopsis raciborskii produzem toxinas hepatotóxicas e neurotóxicas que podem prejudicar animais e seres humanos pela ingestão, uso ou contato com a água. A origem desses problemas está relacionada à ocupação humana, em particular ao 
aporte de dejetos provenientes de sistemas integrados de criação de suínos, e também de fontes não pontuais de poluição agrícola, que tornaram o lago eutrofizado. Esses problemas foram minimizados por meio da integração de fiscalização, adequação de instalações de suinocultura e encerramento de unidades inadequadas; porém, a qualidade das águas na bacia ainda não é ideal (Bacia..., 2002; Pereira \& Moro, 2012).

Neste âmbito, a correlação entre qualidade das águas em bacias hidrográficas e padrões de uso das terras, características da paisagem e preservação de áreas ripárias tem sido motivo de atenção na literatura (Chaves \& Santos, 2009; Lee et al., 2009; Chaves, 2010; Nielsen et al., 2012; Alukwe \& Dillaha, 2014). Em bacias hidrográficas da Coreia do Sul, Lee et al. (2009) verificaram que áreas com agricultura em regiões declivosas exercem forte influência negativa sobre a qualidade das águas, sendo o teor de nitrogênio amoniacal e a demanda bioquímica de oxigênio (DBO) os parâmetros mais afetados. Tundisi et al. (2008), Silva et al. (2010) e Galatto et al. (2011) destacaram a influência negativa de construções rurais próximas a corpos hídricos.

Chaves \& Santos (2009) observaram, em uma bacia no Distrito Federal, que apesar do uso do solo e da fragmentação da paisagem terem aumentado significativamente durante o período estudado, apenas a demanda química por oxigênio (DQO) aumentou de forma significativa. Como a zona ripária se manteve relativamente íntegra, naquele estudo, os autores sugerem que ela pode ter amenizado eventuais impactos à qualidade da água da bacia.

Assim, a qualidade das águas em mananciais é influenciada diretamente pelos padrões de uso das terras nas bacias hidrográficas e nas áreas ripárias. Sobretudo nessas últimas, os fluxos de nutrientes e agrotóxicos nas águas de percolação e de escoamento passam por filtragem química e por processamento microbiológico, o que reduz sua turbidez e a presença de contaminantes (Anbumozhi et al., 2005; Phua \& Minowa, 2005), o que evidencia a importância dessas áreas para a manutenção da qualidade das águas.

Áreas ripárias são, ao menos parcialmente, protegidas pela legislação brasileira, que determina uma distância mínima da margem dos rios como Área de Preservação Permanente (APP), além das de nascentes e encostas com declive superior a $100 \%$ e topos de morro - Lei 4.471/1965 (Brasil, 1965), modificada pela Lei 12.561/2012 (Brasil, 2012). Tratase de áreas protegidas com o objetivo de preservar os recursos hídricos, a paisagem, a estabilidade geológica e a biodiversidade, facilitar o fluxo gênico de fauna e flora, proteger o solo.

Apesar da influência dos padrões uso do solo na qualidade das águas de mananciais, estudos dessa natureza sobre bacias hidrográficas no Brasil são pouco difundidos e existe uma lacuna sobre esta correlação espacialmente organizada, aplicada ao gerenciamento dos recursos hídricos, bem como sobre a influência do uso do solo em áreas ripárias (APPs) na qualidade das águas. A degradação generalizada dos recursos hídricos no país, potencialmente agravada pela revogação do Código Florestal (Brasil, 1965), substituído pela lei 12.561/2012 (Brasil, 2012), demonstra a importância destes estudos como base para planejamento e manejo das bacias (Tundisi \& Tundisi, 2010).

O objetivo deste trabalho foi determinar a relação dos indicadores de qualidade da água com o regime de chuvas e os padrões de uso da terra.

\section{Material e Métodos}

Por sua importância como manancial de abastecimento da cidade de Ponta Grossa, PR, a bacia hidrográfica da represa do Alagados $\left(375,7 \mathrm{~km}^{2}\right)$, na porção superior da bacia do Rio Pitangui, foi definida como área de estudo (Figura 1). A bacia está assentada sobre embasamento geológico complexo, no limite entre o Primeiro e Segundo Planalto do Estado, com predomínio de rochas graníticas do Proterozoico Superior e areníticas do Devoniano, complementado por outras rochas ígneas e metamórficas do PréCambriano. Nas porções alagáveis dos rios Pitangui e Jotuba ocorrem depósitos sedimentares do Holoceno (Figura 2).

Na porção correspondente ao Primeiro Planalto, os solos apresentam textura mais fina, com equilíbrio entre solos pouco desenvolvidos, Cambissolos Háplicos em particular, e mais desenvolvidos, Nitossolos Háplicos, Latossolos Bruno, Latossolos Vermelho e Argissolos Vermelho-Amarelos, de acordo com o relevo, posição na paisagem e geologia. No Segundo Planalto ocorrem principalmente Cambissolos Háplicos, Neossolos Litólicos derivados de arenitos, com textura arenosa e pouco desenvolvidos, também Latossolos Vermelhos e Argissolos Vermelho-Amarelos, nas áreas de várzeas

Pesq. agropec. bras., Brasília, v.51, n.9, p.1172-1183, set. 2016 DOI: 10.1590/S0100-204X2016000900017 
dos rios Pitangui e Jotuba são observados Gleissolos Melânicos (Figura 2). O clima é do tipo Cfb, segundo a classificação de Koeppen, com ocorrência anual de geadas, temperaturas médias entre 13 e $21^{\circ} \mathrm{C}$ e precipitação média de $1.500 \mathrm{~mm}$ (Maack, 1968).

A vegetação original na bacia era formada por elementos de Estepe Gramíneo-Lenhosa (Campos Nativos), distribuídos entre os divisores de águas e porção superior das encostas, e da Floresta Ombrófila Mista (Floresta com Araucária) nos fundos de vale e planícies aluviais. Metade da superfície da bacia hidrográfica encontra-se ocupada por atividades antrópicas (Rocha \& Weirich Neto, 2010).

A fim de avaliar a influência do uso do solo na qualidade das águas foram selecionadas quatro subbacias (Figura 1): Jotuba 1 (J1), compreendendo a porção superior da bacia do Rio Jotuba; Jotuba 2 (J2) compreendendo toda a bacia deste rio; Pitangui 1 (P1), compreendendo a porção superior da bacia do Rio
Pitangui; Pitangui 2 (P2), compreendendo toda a bacia deste rio. Os locais de amostragem foram nos exutórios das respectivas bacias com o objetivo de acessar o efeito do uso do solo na parte superior das bacias (P1 e J1), que apresentam maior cobertura florestal e uso menos intensivo das terras, e antes do deságue destes rios na represa ( $\mathrm{P} 2$ e J2), para poder acessar o potencial efeito do uso do solo sobre a qualidade das águas na totalidade da bacia (Figura 1).

O uso do solo foi classificado na área total das bacias hidrográficas e nas APPs. A nova lei da Vegetação Brasileira (Brasil, 2012) prevê, para rios com até 10 metros de largura, a manutenção de uma faixa de 30 metros ao longo de cada margem do rio, variável em função do tamanho do imóvel rural, caracterizada como APP sob vegetação nativa. Na bacia predominam amplamente propriedades maiores que o limite de quatro módulos fiscais definidos pela legislação e,
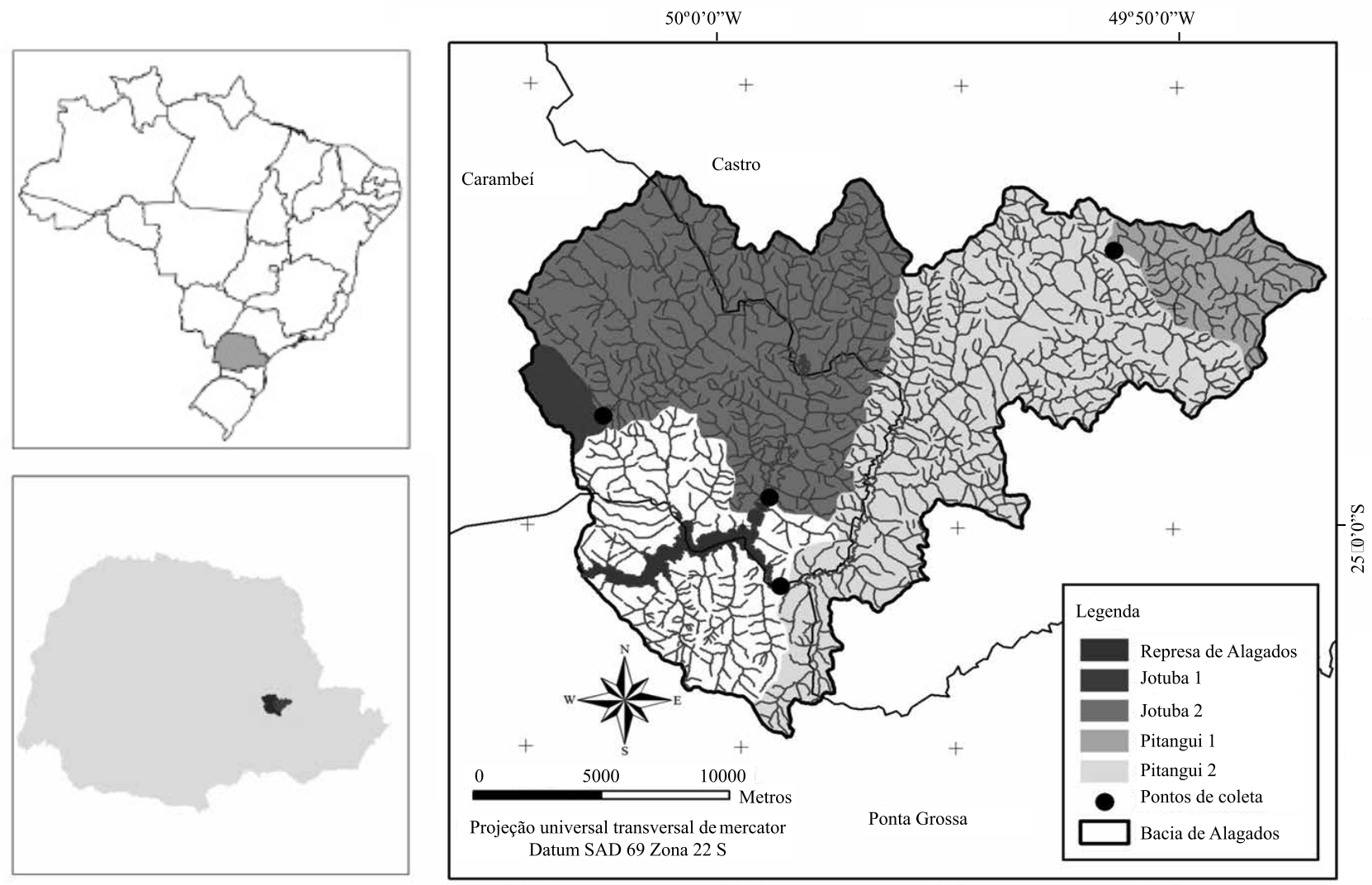

Figura 1. Localização da bacia hidrográfica de Alagados e das bacias hidrográficas avaliadas com os respectivos pontos de coleta de amostras. A área destacada no mapa do Paraná refere-se à totalidade da bacia do Rio Pitangui, que engloba a bacia de Alagados e mais uma porção a oeste. 

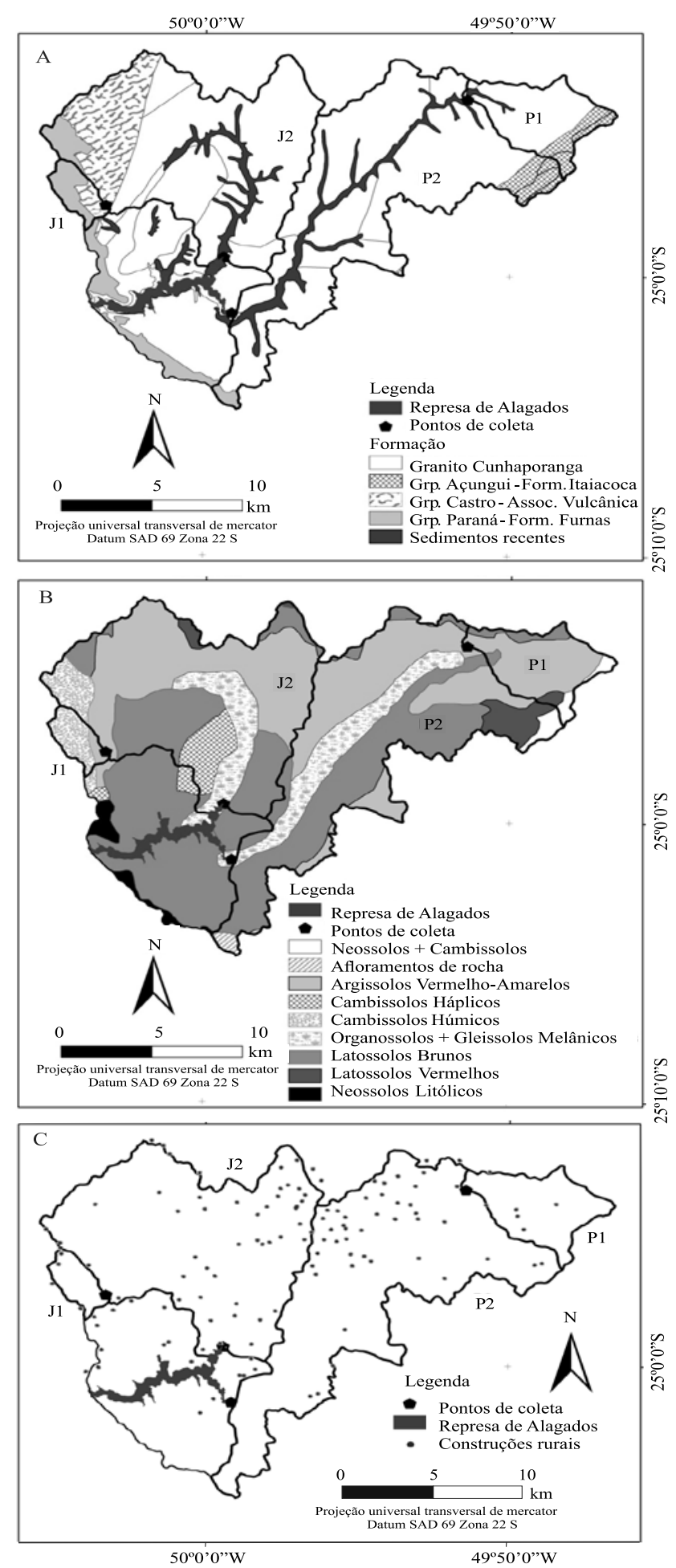

Figura 2. Mapa geológico (A), pedológico (B) e localização de construções rurais (C) na bacia da represa de Alagados, PR. Os mapas geológico e pedológico utilizados para gerar os mapas da bacia foram obtidos do ITCG, e a localização das construções rurais foi obtida do relatório realizado pelo Núcleo de Estudos do Meio Ambiente (Bacia..., 2002). Grp., grupo; Form., formação; Assoc., associação. portanto, definiu-se neste estudo uma faixa de 30 metros para definição das APPs.

Para a classificação do uso do solo, foi utilizado o software ArcGis 10.2 (ESRI). Foram utilizadas 24 ortofotos coloridas com alta resolução espacial $(0.8$ x 0,8 metros) datadas de 2002 para a construção de mosaico. A fim de determinar o uso do solo na área total das bacias, foi realizada classificação dos dados utilizando-se o algoritmo máxima verossimilhança. Para maior precisão do mapeamento do uso do solo nas APPs, considerando faixa de 30 metros em ambas as margens do rio, foi realizada a interpretação visual das imagens.

$\mathrm{Na}$ confirmação e atualização dos dados, foram utilizadas imagens do Google Earth de maio de 2011. As unidades mapeadas foram classificadas em três classes de uso do solo: Florestas, Campos e Agricultura. As áreas de campos incluem campos nativos e pastagens; as áreas de floresta incluem florestas nativas e cultivadas. Nas áreas de agricultura, ocorre o predomínio do Sistema Plantio Direto (SPD) com uso intensivo de fertilizantes químicos e orgânicos, agrotóxicos e mecanização (Rocha \& Weirich Neto, 2010).

A bacia J1 apresenta expressiva superfície cultivada e expressiva cobertura florestal ao longo da hidrografia principal, encaixada em fundo de vale escarpado associado a lineamento estrutural. J2 apresenta significativa cobertura florestal na porção superior da bacia e predomínio de áreas intensivamente cultivadas na porção a jusante. P1 apresenta cobertura florestal significativa e áreas cultivadas em sua porção central enquanto P2 apresenta áreas cultivadas intercaladas com áreas de floresta distribuídas na bacia.

As bacias P2 e J2 apresentam concentração de construções rurais em sua porção mediana (Figura 2), incluindo residências e instalações para suínos, bovinos de leite e corte, aves, ovinos e caprinos (Bacia..., 2002). As áreas cultivadas nas bacias foram em geral implantadas em superfícies previamente cobertas por campos (J1, J2 e P2), mas também em várzeas drenadas (P2), e florestas nativas (P1) (Rocha \& Weirich Neto, 2010).

Para avaliar a qualidade das águas nas bacias, foram utilizados os seguintes parâmetros: temperatura do ar, temperatura da água (ambas foram medidas utilizando-se termômetros de mercúrio instalados nos pontos de coleta), $\mathrm{pH}$, turbidez, nitrogênio amoniacal, condutividade elétrica, fósforo total, fósforo reativo, 
nitrato, OD (oxigênio dissolvido), DQO (demanda química de oxigênio) e DBO (demanda bioquímica de oxigênio), todos os parâmetros foram analisados conforme as metodologias do "Standard methods for the examination of water and watershed" (2005). Esses dados foram cedidos pela Sanepar e são provenientes do monitoramento das bacias hidrográficas. As amostras foram coletadas mensalmente em todos os pontos de coleta (Figura 1) com frascos de plásticos e após, enviadas para a realização das análises laboratoriais. Foram utilizados dados referentes a quatro anos, entre 2008 e 2011.

$\mathrm{Na}$ determinação da qualidade das águas, foi calculado o $\mathrm{IQA}_{\mathrm{b}}$ (Índice de qualidade das águas de Bascarán), e uma descrição do índice pode ser encontrada em Rizzi (2001) e Molozzi et al. (2006). Resumidamente, o IQA $\mathrm{b}_{\mathrm{b}}$ é obtido por meio da seguinte equação: $\mathrm{IQA}_{\mathrm{b}}=\mathrm{k}\left[\left(\sum \mathrm{Ci} \times \mathrm{Pi}\right) / \sum \mathrm{Pi}\right]$, em que: $\mathrm{k}$ é uma constante função do aspecto visual da água (para o presente trabalho foi utilizado o valor 1,0; Ci é um valor percentual proveniente de uma escala de classificação para cada parâmetro; Pi é o peso de cada parâmetro utilizado no índice. Tabelas com os valores de $\mathrm{Ci}$ e Pi podem ser obtidas em Rizzi (2001).

$\mathrm{O}_{\mathrm{IQA}}$ varia de 1 a 100 e classifica a qualidade das águas como: péssima (0-10), muito ruim (1020), ruim (20-30), desagradável (30-40), imprópria (40-50), normal (50-60), aceitável (60-70), agradável (70-80), boa (80-90), muito boa (90-99) e excelente (100). O índice foi escolhido por sua flexibilidade com relação aos parâmetros que podem ser considerados para o cálculo. Dessa forma, podem-se utilizar todos os parâmetros disponíveis na base de dados.

A pluviosidade mensal durante o período analisado também foi incorporada à análise para auxiliar a interpretação da variabilidade temporal da qualidade das águas. A incidência de chuvas aumenta o carreamento de poluentes que contribuem para a diminuição da qualidade das águas dos rios. A pluviosidade foi monitorada pela Sanepar, com a utilização de pluviômetros instalados na represa de Alagados. Em alguns meses do período estudado, esta informação não estava disponível, então os dados foram complementados com auxílio da base do Iapar, que realiza o monitoramento de variáveis climáticas em estações meteorológicas. Neste trabalho foi utilizada a Estação Meteorológica de Ponta Grossa (2513' S; $50^{\circ} 01^{\prime}$ W) (Iapar, 2013).
Os dados sobre a qualidade das águas foram agrupados de acordo com os períodos de cultivo das safras de verão, de modo a incorporar períodos com maior precipitação pluvial somada ao manejo intensivo das áreas cultivadas, aplicação de fertilizantes, agrotóxicos e mobilização do solo; e de inverno, de modo a incorporar períodos com menor precipitação pluvial, correspondendo à formação de pastagens de inverno e manejo menos intensivo do solo. Como períodos de verão, foram considerados os meses entre outubro e março, e inverno, os meses entre abril e setembro.

\section{Resultados e Discussão}

A média dos valores mensais de IQA $\mathrm{A}_{\mathrm{b}}$ observadas entre 2008 e 2011 das amostras das quatro bacias hidrográficas contribuintes da represa dos Alagados foi igual a 70,4 $\pm 10,0$ (Tabela 1), e a água classificada como de boa qualidade. Os valores extremos variaram entre 41 (qualidade imprópria) e 93 (qualidade muito boa), e a mediana igual a 71,5. A média mais elevada para IQA $A_{b}(77,6)$ ocorreu no inverno de 2011 e a mais baixa $(60,1)$ no verão 2009/2010. Na sub-bacia do rio Jotuba, a média dos valores de IQA $\mathrm{A}_{\mathrm{b}}$ foi 73 (qualidade boa), ligeiramente superior à do rio Pitangui com média 69 (agradável).

As sub-bacias situadas a montante, J1 (Jotuba 1) e P1 (Pitangui 1), apresentaram média de IQA $\mathrm{I}_{\mathrm{b}}$ superior às das bacias a jusante $\mathrm{J} 2$, (Jotuba 2) e P2 (Pitangui 2). Sistematicamente, ao longo do período de estudo, $\mathrm{J} 1$ apresentou a maior média de $\mathrm{IQA}_{\mathrm{b}}$ em relação às demais. Nos meses de inverno, os valores de IQA foram maiores em todas as bacias, coincidindo com o período de menor precipitação pluviométrica. A Figura 3 demonstra graficamente a variabilidade temporal dos valores de IQA $\mathrm{A}_{\mathrm{b}}$, nas quatro bacias, e sua relação com a distribuição das chuvas.

Os índices de qualidade das águas nessas bacias apresentaram padrões semelhantes ao longo do estudo, com nítida flutuação entre valores mais elevados de $\mathrm{IQA}_{\mathrm{b}}$ no inverno e menores no verão, correspondendo ao padrão de distribuição das chuvas na região, com inverno ligeiramente menos úmido que o verão. Além da menor pluviosidade, outro fator associado aos maiores valores de IQA $\mathrm{b}_{\mathrm{b}}$ no inverno é o manejo menos intensivo das áreas cultivadas no período (Rocha \& Weirich Neto, 2010). 


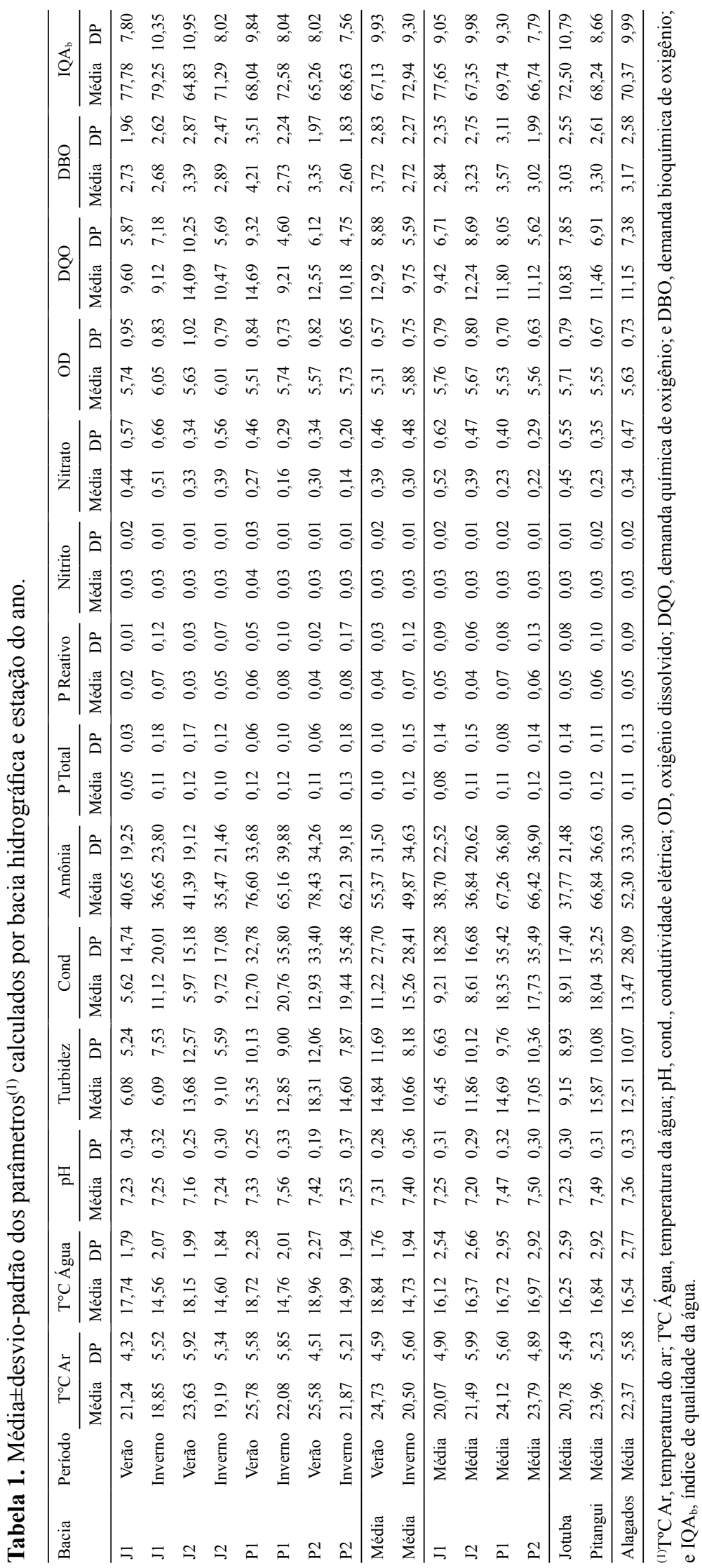


No calendário agrícola anual, o verão corresponde à estação com uso e manejo mais intensivo dos solos cultivados, incluindo manuseio de fertilizantes e agroquímicos, o que, associado à maior pluviosidade, contribui para o maior aporte de poluentes aos corpos hídricos. Assim, no verão 2009/2010, período de maior precipitação observada (média mensal 191 $\mathrm{mm}$ ), ocorreram os menores valores de IQA $\mathrm{b}_{\mathrm{b}}$ em todas as bacias. No inverno seguinte (2010), o mais seco do período (média mensal $98 \mathrm{~mm}$ ), observaram-se melhorias significativas na qualidade das águas das quatro bacias.

Culturas de inverno, trigo (Triticum aestivum), aveia (Avena strigosa) e o azevém (Lolium multiflorium), são manejadas nas bacias com menores quantidades de fertilizantes e agrotóxicos, além de demandarem trânsito menos intensivo de equipamentos agrícolas. Por sua vez, o emprego de cultivo mínimo, prática regional comum na implantação da cultura de inverno pode contribuir para a contaminação quando coincidir com precipitação intensiva.

Os dados de pluviosidade ajudam a compreender parte da variação temporal nos índices de qualidade das águas. $\mathrm{O}$ maior volume de precipitação nos meses de verão, marcado por chuvas mais intensivas, acentua o escoamento superficial, processos erosivos em áreas agrícolas e estradas rurais e o carreamento de sedimentos, resíduos de fertilizantes químicos, orgânicos e agrotóxicos. Também ocorre maior infiltração de poluentes através dos poros do solo e consequente escoamento sub-superficial (Ahearn et al., 2005; Anbumozhi et al., 2005; Pratt \& Chang, 2012; Poudel et al., 2013).

Além da variabilidade proporcionada pelo regime de chuvas, observaram-se diferenças entre os valores de IQA $_{b}$ nas bacias hidrográficas. Considerando que

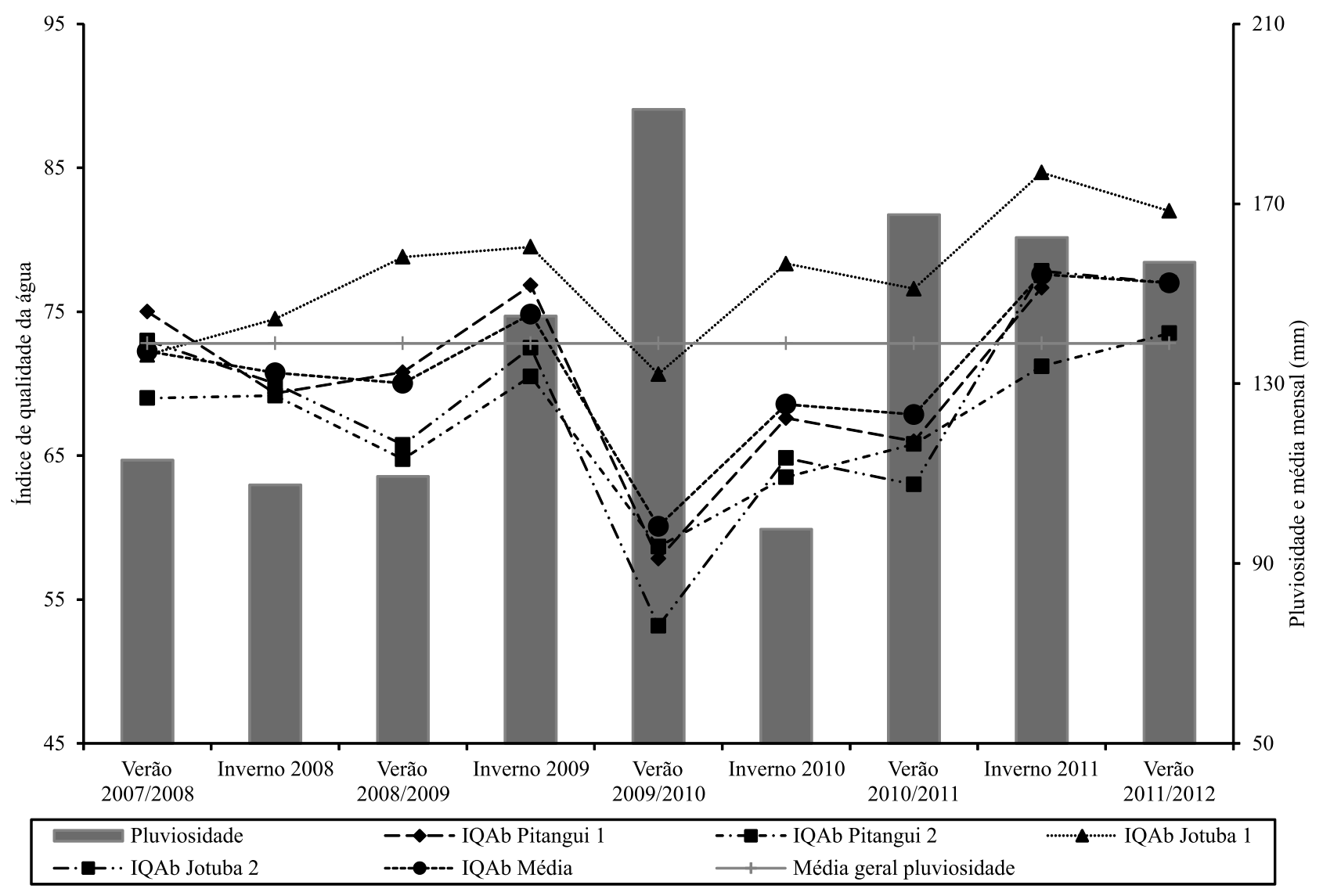

Figura 3. Pluviosidade e valores de índice de qualidade da água $\left(\mathrm{IQA}_{\mathrm{b}}\right)$ observados nas bacias hidrográficas, agrupados de acordo com os períodos de inverno e verão, nos meses de abril a setembro, e de outubro a março, respectivamente. 
os regimes de chuvas nas bacias são similares, esta variabilidade foi interpretada a partir da influência potencial dos padrões de uso das terras nas sub-bacias e respectivas áreas de preservação permanente.

A Figura 4 apresenta dados de uso das terras por subbacia: a) áreas com cobertura florestal, principalmente florestas nativas em diferentes estágios de sucessão ecológica e também áreas reflorestadas (Pinus spp. e Eucalyptus spp.), em P1 (60\%), P2 (41\%) e J2 $(58 \%)$; b) paisagens campestres, incluindo campos nativos remanescentes e pastagens manejadas para a pecuária de leite, campos úmidos e várzeas, principalmente em P2 (38\%) e J1 (21\%); e c) áreas cultivadas, principalmente em J1 (47\%), J2 (21\%) e P2 (21\%). Em valores absolutos, enquanto J1 e P1 apresentavam cerca de 350 ha com áreas cultivadas, J2 e P2 apresentavam expressivos 2.907 e 3.480 ha, respectivamente.

Em relação às APPs, destaca-se a expressiva cobertura com vegetação nativa remanescente, entre $92 \%$ a $96 \%$ da superfície total, incluindo remanescentes florestais (63 e 74\%) e campestres (18 a 28\%) (Figura 4). Embora a vegetação original tenha sido bastante alterada no âmbito das sub-bacias, nas APPs a vegetação nativa tem sido mantida em função das limitações do uso agrícola intensivo dessas áreas (Rocha \& Weirich Neto, 2010). Áreas cultivadas (irregularmente) em APPs totalizaram 7,5 ha (8\%) em J1; 17 ha (4\%) em P1; 149 ha (7\%) em $\mathrm{J} 2$; 108 ha (4\%) em P2.

A bacia J1 apresentou o melhor índice de qualidade das águas, a menor cobertura remanescente (florestal, $20 \%$ e campestre, $33 \%$ ) e o maior porcentual de área sob cultivo (47\%). As áreas cultivadas nesta bacia (356 ha) foram implantadas em áreas de campos nativos localizadas em paisagens com altitudes elevadas, delimitadas principalmente por áreas formadas por campos e campos úmidos remanescentes. Em relação ao uso das terras nas APPs, J1 apresenta expressiva cobertura florestal (74\%) e campestre (18\%); as áreas cultivadas em APPs totalizam 7,0 ha (8\%).
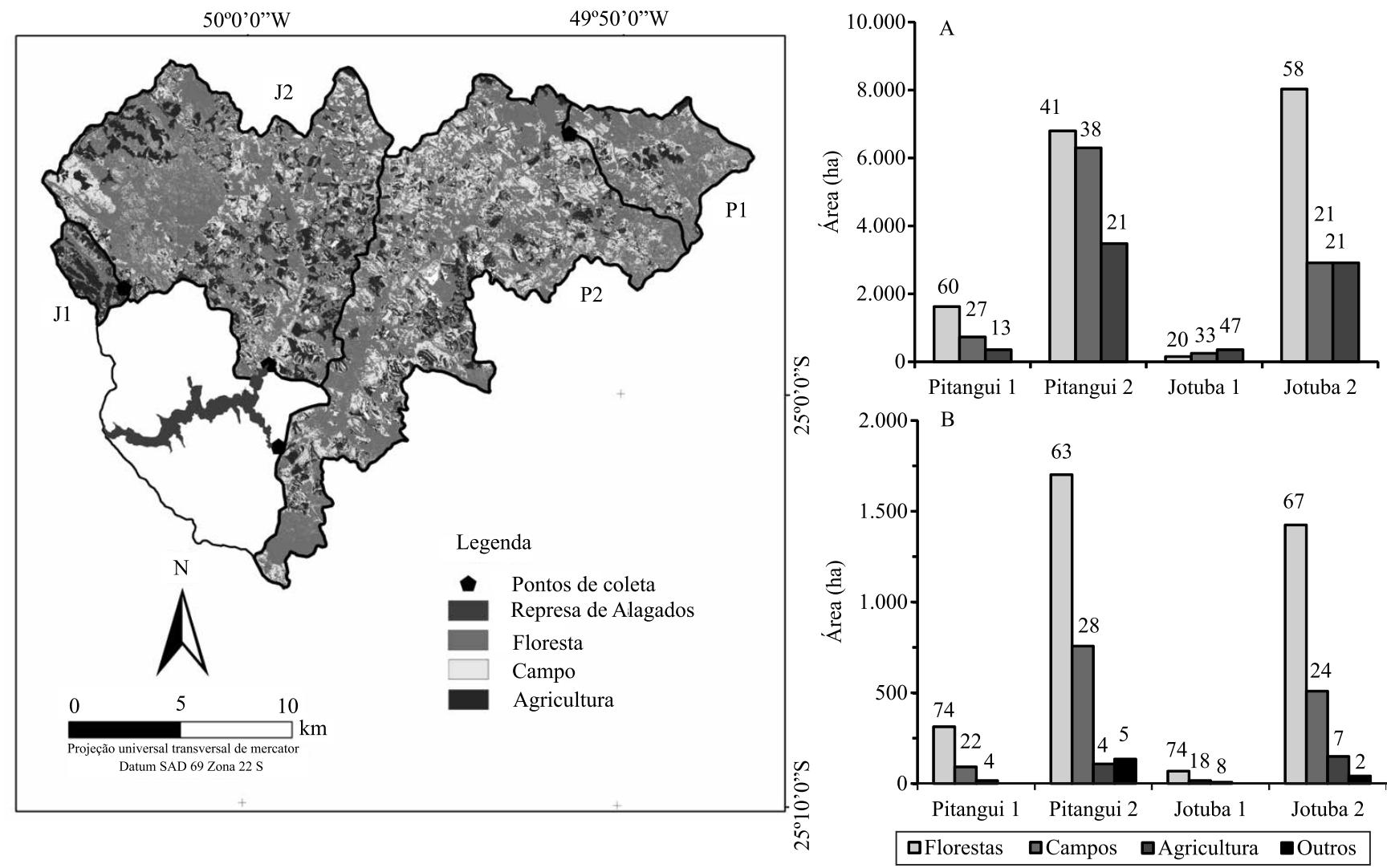

Figura 4. Mapa de uso do solo e uso do solo na área total das sub-bacias (A) e nas áreas de preservação permanente (B). Os valores acima das colunas são os percentuais de cada local. 
A melhor qualidade das águas em J1 pode estar associada à geomorfologia da cobertura sedimentar devoniana, em que fraturas e lineamentos estruturais orientam a formação de vales encaixados e profundos, encostas dissecadas com sucessão de Neossolos e Cambissolos húmicos e interflúvios com solos mais desenvolvidos. Assim, poluentes carreados das áreas cultivadas, localizadas essencialmente na porção superior da paisagem, podem estar sendo filtrados pelas partículas e matéria orgânica dos solos e pela cobertura sedimentar arenosa, antes de alcançar o corpo hídrico. A cobertura remanescente de campos úmidos na porção intermediária das encostas, e florestal pouco perturbada, nos fundos de vales, também deve estar contribuindo para minimizar a contribuição da poluição difusa.

A bacia P1 apresentou a maior taxa $(87 \%)$ de cobertura remanescente (florestal $60 \%$ e campestre $27 \%$ ), tanto na bacia quanto nas APPs (74\% floresta e $22 \%$ campos). Assim, os valores mais elevados de IQA em relação a $\mathrm{J} 2$ e $\mathrm{P} 2$ podem ser relacionados ao uso menos intensivo das terras em P1. As áreas agrícolas, desenvolvidas sob sistema plantio direto, totalizam 352 ha $(13 \%)$ e foram implantas principalmente em paisagens com relevo suave e solos mais desenvolvidos (Latossolos Bruno e Vermelho e Nitossolos Háplicos), com textura argilosa, originados a partir de rochas graníticas, fatores que contribuem para melhoria das condições de filtragem de poluentes.

A presença de agricultura intensiva em ambientes sedimentares e drenagem de Organossolos e Gleissolos, no terço inferior da bacia $\mathrm{P} 1$, compromete o serviço ambiental de filtragem proporcionado por esses componentes da paisagem e afeta diretamente a qualidade do corpo hídrico. Incluem-se neste contexto, 17 ha $(4 \%)$ de APPs sob cultivo intensivo. Este padrão de uso das terras pode estar comprometendo a qualidade da água em P1, quando comparada aos índices observados em $\mathrm{J} 1$.

As bacias $\mathrm{J} 2$ e P2 apresentaram padrões de uso dos solos das terras semelhantes ( $21 \%$ cultivado) e índices de qualidade de água inferior às respectivas bacias situadas a montante. Nessas bacias, a área cultivada é expressiva: 3.480 ha $(21 \%)$ no total da bacia e 149 ha (7\%) em APPs em J2; e 2.907 ha (21\%) na bacia e 108 ha (4\%) em APPs em P2. Em ambas, extensas áreas com Organossolo Mésico e Gleissolo Melânico foram drenadas para cultivo agrícola intensivo. A existência de agrupamentos de estabelecimentos rurais na porção mediana dessas bacias (Figura 2), além de construções, moradias e uma linha férrea também podem estar contribuindo com aporte de poluentes (Bacia..., 2002).

A elevada aplicação de fertilizantes fosfatados e nitrogenados nas áreas cultivadas em J2 e P2 contribui para o aumento do teor de fósforo e nitrato nos corpos hídricos. Apesar de o P ficar fortemente retido nas argilas de solos tropicais e subtropicais, pode ocorrer seu aporte ao rio via erosão do solo, além da lixiviação de fósforo orgânico oriundo de dejetos animais. Também deve ocorrer contaminação pelo aporte de dejetos das áreas de campos utilizadas para a pecuária próximas aos rios, bem como por meio da elevada produção de dejetos dos sistemas intensivos de criação animal.

No âmbito dessas duas bacias, o cultivo intensivo ocorre principalmente em solos mais profundos, com textura argilosa, o que pode contribuir para a retenção de poluentes; a adoção maciça do sistema plantio direto como estratégia de manejo, acréscimo de carbono e controle de erosão também podem estar contribuindo para minimizar o impacto das áreas cultivadas nos valores de $\mathrm{IQA}_{\mathrm{b}}$, evidenciando o papel-chave dos solos na manutenção da qualidade da água em corpos hídricos.

Com base nos dados obtidos neste estudo, destacase a importância das APPs ao longo dos ecossistemas ripários nas bacias analisadas. Observou-se que as áreas cultivadas próximas aos corpos hídricos, mesmo em pequenas proporções influenciaram mais a qualidade das águas que o total de áreas cultivadas na bacia. $\mathrm{O}$ fator mais evidente para explicar esta variação é a área sob cultivo agrícola em valores absolutos (ha) nas APPs. O impacto da poluição pode ser significativo mesmo que as áreas de aporte de poluentes sejam pequenas em valores relativos à superfície total das bacias.

A importância de áreas de proteção ao redor de rios e lagos para promover a qualidade das águas é amplamente reconhecida (Anbumozhi et al., 2005; Tundisi et al., 2008; Galatto et al., 2011; Nielsen et al., 2012; Pratt \& Chang, 2012), destacando-se a importância destas na diminuição do aporte de sedimentos, filtragem de nutrientes e agrotóxicos de áreas cultivadas.

Como observamos em P2 e J2, e mesmo em P1, a filtragem de poluentes não é tão eficiente como em J1, 
indicativo de que a proteção das APPs e de várzeas e outras áreas úmidas, deve ser o principal mecanismo para promoção da proteção hídrica na bacia Alagados. Os resultados de Chaves \& Santos (2009) corroboram esse mecanismo de proteção. Os autores analisaram o uso do solo, a fragmentação da paisagem e a qualidade da água em bacia hidrográfica no Distrito Federal.

Contrariamente, em trabalho relacionando uso do solo e qualidade das águas de lagos na Dinamarca (Nielsen et al., 2012), a correlação foi maior com a proporção de uso agrícola na bacia total do que nas áreas ripárias. $\mathrm{O}$ histórico uso intensivo das terras, o elevado aporte de nutrientes e matéria orgânica nas condições daquele país, demanda, conforme estes autores, a redução das áreas cultivadas nas bacias para reduzir a concentração de nutrientes nos ecossistemas de lagos.

De modo similar, Sliva \& Williams (2001) observaram, em áreas cultivadas intensivamente no Canadá, que a composição total da paisagem afetou mais a qualidade das águas do que uma faixa com $100 \mathrm{~m}$ de proteção marginal aos rios. Estes autores destacam a importância de áreas florestais na paisagem, não somente ao redor dos corpos hídricos, para a manutenção da qualidade das águas.

A análise da correlação de padrões de uso das terras e indicadores de qualidade da água é complexa já que diversos fatores (multicolinearidade) estão simultaneamente influenciando os resultados ao longo do tempo (Poudel et al., 2013; Ekness \& Randhir, 2015). Assim, no verão de 2009 foram observados os menores valores de IQA $\mathrm{b}_{\mathrm{b}}$ para todas as bacias, o que coincide com o período de maior precipitação observado, mas também com uma alta ocorrida no preço da soja e aumento na área plantada em relação ao ano anterior (Cepea, 2011; Paraná, 2013).

Em 2011 foram observadas as melhores médias de $\mathrm{IQA}_{\mathrm{b}}$ em todas as bacias, coincidindo com queda no preço da safra de soja em 2010 (Cepea, 2011), com diminuição da área plantada desta cultura no âmbito regional em 2011 (Paraná, 2013). Isso também pode ter estimulado produtores a evitar doses maiores de fertilizantes e o cultivo em áreas marginais com solos menos produtivos, diminuindo assim o fluxo de nutrientes para os corpos hídricos, mesmo em período com alta pluviosidade. Também a elevada declividade no curso superior das bacias em J1 e P1 indica velocidades mais acentuadas, o que promove oxigenação e melhoria na qualidade das águas em relação às bacias com relevos mais planos situados a jusante.

A variabilidade dos padrões de $\mathrm{IQA}_{\mathrm{b}}$ observada neste estudo, entre bacias, valores extremos e em acordo com as estações do ano, evidencia a necessidade de gerenciamento do uso das terras no âmbito da bacia hidrográfica para que sejam mantidos padrões desejáveis de vazão e qualidade das águas do manancial. A crise hídrica vivenciada em diversas regiões do Brasil e o agravamento das condições climáticas reforça esta necessidade. As ações de cada proprietário são importantes, não só porque afetam uma porção da bacia em particular, mas também porque afetam as terras vizinhas e a saúde dos ecossistemas aquáticos e das bacias hidrográficas em que ocorrem.

Estudos de caso como este devem ser estimulados em inúmeras bacias hidrográficas no Brasil para que possam ser produzidos referenciais de dados para a análise multivariada da correlação entre uso das terras, precipitação e qualidade das águas. Esses dados irão propiciar parâmetros mais adequados para definição da largura necessária para proteção das APPs em cada caso e a intensidade de uso das terras como função da qualidade desejável das águas. Esses dados espacialmente organizados serão parâmetro básico para a definição das estratégias para a conservação no âmbito local.

Assim podem ser definidas áreas prioritárias para conservação em bacias mananciais e estratégias para pagamentos por serviço ambiental (Chaves, 2010; Poudel et al., 2013; Rocha et al., 2014; Ekness \& Randhir, 2015), relevantes para o planejamento de utilização do solo e consequente desenvolvimento de políticas públicas para proteção dos recursos hídricos do País.

\section{Conclusões}

1. As bacias com maiores superfícies cultivadas apresentam, de modo geral, qualidade de água inferior, e a área total cultivada nas APPs tem efeito negativo sobre a qualidade das águas.

2. A qualidade das águas diminui nos períodos de verão, que apresentam maior precipitação e manejo mais intensivo dos solos.

3. A variabilidade dos padrões de IQA entre as bacias, bem como de acordo com as estações do ano,

Pesq. agropec. bras., Brasília, v.51, n.9, p.1172-1183, set. 2016 DOI: 10.1590/S0100-204X2016000900017 
evidencia a necessidade de gerenciamento do uso das terras, particularmente no âmbito das APPs, para que sejam mantidos padrões desejáveis de vazão e qualidade das águas no manancial.

\section{Agradecimentos}

À CompanhiadeSaneamentodo Paraná(Sanepar), em especial à química Andressa Beló, pela disponibilização dos dados referentes ao monitoramento da qualidade das águas; e ao Nucleam, em especial ao professor Fernando Pillati, pela disponibilização dos relatórios de uso das terras na bacia.

\section{Referências}

AHEARN, D.S.; SHEIBLEY, R.W.; DAHLGREN, R.A.; ANDERSON, M.; JOHNSON, J.; TATE, K.W. Land use and land cover influence on water quality in the last free-flowing river draining the western Sierra Nevada, California. Journal of Hydrology, v.313, p.234-247, 2005. DOI: 10.1016/j.jhydrol.2005.02.038.

ALUKWE, I.A.; DILLAHA, T. Effects of watershed land use data on HSPF water quality in the upper opequon watershed in Northern Virginia, USA. American Journal of Water Resources, v.2, p.5462, 2014. DOI: 10.12691/ajwr-2-3-1.

ANBUMOZHI, V.; RADHAKRISHNAN, J.; YAMAJI, E. Impact of riparian buffer zones on water quality and associated management considerations. Ecological Engineering, v.24, p.517523, 2005. DOI: 10.1016/j.ecoleng.2004.01.007.

BACIA hidrográfica do manancial alagados. Ponta Grossa: Universidade Estadual de Ponta Grossa, Núcleo de Estudos em Meio Ambiente, 2002. Relatório.

BRASIL. Lei $\mathrm{n}^{\circ} 4.771$, de 15 de setembro de 1965. Institui o novo código florestal. Diário Oficial [da] República Federativa do Brasil, Brasília, DF, 16 set. 1965.

BRASIL. Lei $n^{\circ} 12.651$, de 25 de maio de 2012. Dispõe sobre a proteção da vegetação nativa; altera as Leis nos 6.938, de 31 de agosto de 1981, 9.393, de 19 de dezembro de 1996, e 11.428, de 22 de dezembro de 2006; revoga as Leis nos 4.771, de 15 de setembro de 1965, e 7.754, de 14 de abril de 1989, e a Medida Provisória no 2.166-67, de 24 de agosto de 2001; e dá outras providências. Diário Oficial [da] República Federativa do Brasil, Brasília, DF, 28 maio 2012.

CEPEA. CENTRO DE ESTUDOS AVANÇADOS EM ECONOMIA APLICADA. Agromensal: soja. 2011. Disponível em: $\quad<$ http://www.cepea.esalq.usp.br/agromensal/2011/12_ dezembro/Soja.htm>. Acesso em: 5 dez. 2013.

CHAVES, H.M.L. Relações de aporte de sedimento e implicação de sua utilização no pagamento por serviço ambiental em bacias hidrográficas. Revista Brasileira de Ciência do Solo, v.34, p.1469-1477, 2010. DOI: 10.1590/S0100-06832010000400043.

CHAVES, H.M.L.; SANTOS, L.B. dos. Ocupação do solo, fragmentação da paisagem e qualidade da água em uma pequena bacia hidrográfica. Revista Brasileira de Engenharia Agrícola e Ambiental, v.13, p.922-930, 2009. DOI: 10.1590/S141543662009000700015.

EKNESS, P.; RANDHIR, T. Effect of climate and land cover changes on watershed runoff: a multivariate assessment for storm water management. Journal of Geophysical Research: Biogeosciences, v.120, p.1785-1796, 2015. DOI: 10.1002/2015JG002981.

GALATTO, S.L.; ALEXANDRE, N.Z.; PEREIRA, J.L.; PATRÍCIO, T.B.; VASSILIOU, M.; FERNANDES, A.N.; FRASSETTO, J.; VALVASSORI, M.L. Diagnóstico ambiental de nascentes no município de Criciúma, Santa Catarina. Revista de Ciências Ambientais, v.5, p.39-56, 2011.

IAPAR. INSTITUTO AGRONÔMICO DO PARANÁ. Redes de estações meteorológicas no Paraná. Disponível em: $<$ http:// www.iapar.br/modules/conteudo/conteudo.php?conteudo=890/>. Acesso em: 10 dez. 2013.

LEE, S.-W.; HWANG, S.-J.; LEE, S.-B.; HWANG, H.-S.; SUNG, H.-C. Landscape ecological approach to the relationships of land use patterns in watersheds to water quality characteristics. Landscape and Urban Planning, v.92, p.80-89, 2009. DOI: 10.1016/j.landurbplan.2009.02.008.

MAACK, R. Geografia física do estado do Paraná. Rio de Janeiro: [s.n.], 1968. 350p.

MOLOZZI, J.; PINHEIRO, A.; SILVA, M.R. da. Qualidade da água em diferentes estágio de desenvolvimento do arroz irrigado. Pesquisa Agropecuária Brasileira, v.41, p.1393-1398, 2006. DOI: $10.1590 / \mathrm{S} 0100-204 X 2006000900007$.

NIELSEN, A.; TROLLE, D.; SØNDERGAARD, M.; LAURIDSEN, T.L.; BJERRING, R.; OLESEN, J.E.; JEPPESEN, E. Watershed land use effects on lake water quality in Denmark, Ecological Applications, v.22, p.1187-1200, 2012. DOI: 10.1890/11-1831.1.

PARANÁ. Secretaria de Agricultura e do Abastecimento. Produção agropecuária: produção agrícola paranaense por município: municípios de Castro e Carambeí. Disponível em: $<$ http://www.agricultura.pr.gov.br/modules/conteudo/conteudo. php?conteudo=137>. Acesso em: 5 dez. 2013.

PEREIRA, T.K.; MORO, R.S. Paisagem ripária fluvial dos rios Pitangui e Jotuva no primeiro planalto paranaense, Ponta Grossa, PR. GEOUSP: Espaço e Tempo, v.31, p.79-93, 2012.

PHUA, M.-H.; MINOWA, M. A GIS-based multi-criteria decision making approach to forest conservation planning at a landscape scale: a case study in the Kinabalu Area, Sabah, Malaysia, Landscape and Urban Planning, v.71, p.207-222, 2005. DOI: 10.1016/j.landurbplan.2004.03.004.

POUDEL, D.D.; LEE, T.; SRINIVASAN, R.; ABBASPOUR, K.; JEONG, C.Y. Assessment of seasonal and spatial variation of surface water quality, identification of factors associated with water quality variability, and the modelling of critical nonpoint source pollution areas in an agricultural watershed. Journal of Soil And Water Conservation, v.68, p.155-171, 2013. DOI: 10.2489/ jswc.68.3.155.

PRATT, B.; CHANG, H. Effects of land cover, topography, and built structure on seasonal water quality at multiple spatial scales. 
Journal of Hazardous Materials, v.209-210, p.48-58, 2012. DOI: 10.1016/j.jhazmat.2011.12.068.

RIZZI, N.E. Índices de qualidade de água. Sanare, v.15, p.11-20, 2001 .

ROCHA, C.H.; SANTOS, E.N.; BARRETO, K.T. Áreas prioritárias para conservação dos recursos hídricos. In: GEALH, A.M.; MELO, M.S. de (Org). Rio São João Carambeí-PR: fonte de vida, cuidados devidos. Ponta Grossa: Ed. da UEPG, 2014.

ROCHA, C.H.; WEIRICH NETO, P.H. Padrões de uso das terras e implicações ambientais. In: GEALH, A.M.; MELO, M.S.; MORO, R.S. (Org.). Pitangui, rio de contrastes: seus lugares, seus peixes, sua gente. Ponta Grossa: UEPG, 2010. p.23-42.

SILVA, D.S. da; GALVÍNCIO, J.D.; ALMEIDA, H.R.R. de C. Variabilidade da qualidade de água na bacia hidrográfica do Rio São Francisco e atividades antrópicas relacionadas. Qualit@s Revista Eletrônica, v.9, p.1-17, 2010. Disponível em: <http:// revista.uepb.edu.br/index.php/qualitas/article/view/687/496>. Acesso em: 5 dez. 2013.

SIIVA, L.; WILLIAMS, D.D. Buffer zone versus whole catchment approaches to studying land use impact on river water quality. Water Research, v.35, p.3462-3472, 2001. DOI: 10.1016/S00431354(01)00062-8.

STANDARD methods for the examination of water and watershed. $21^{\text {th }}$ ed. Washington: American Public Health Association, 2005.

TUNDISI, J.G.; MATSUMURA-TUNDISI, T.; PARESCHI, D.C.; LUZIA, A.P.; VON HEALING, P.H.; FROLLINI, E.H. A bacia hidrográfica do Tietê/Jacaré: estudo de caso em pesquisa e gerenciamento. Estudos Avançados, v.22, p.159-172, 2008. DOI: 10.1590/S0103-40142008000200010.

TUNDISI, J.G.; TUNDISI, T.M. Impactos potenciais das alterações do Código Florestal nos recursos hídricos. Biota Neotropica, v.10, p.67-75, 2010. DOI: 10.1590/S1676-06032010000400010.

Recebido em 16 de julho de 2015 e aprovado em 10 de dezembro de 2015 